Research Article

\title{
Cinnamic Acid Ameliorates Nonalcoholic Fatty Liver Disease by Suppressing Hepatic Lipogenesis and Promoting Fatty Acid Oxidation
}

\author{
You Wu $\mathbb{D},{ }^{1,2}$ Minghui Wang $\mathbb{D}^{3},{ }^{3}$ Tao Yang $\mathbb{D}^{1,2}$ Lingling Qin ${ }^{1},{ }^{4}$ Yaomu Hu $\mathbb{D},{ }^{1,2,5}$ \\ Dan Zhao $\mathbb{D}^{1,2,5}$ Lili Wu $\mathbb{D}^{1,2}$ and Tonghua Liu $\mathbb{D}^{1,2}$ \\ ${ }^{1}$ Key Laboratory of Health Cultivation of the Ministry of Education, Beijing University of Chinese Medicine, \\ Beijing 100029, China \\ ${ }^{2}$ Key Laboratory of Health Cultivation of Beijing, Beijing University of Chinese Medicine, Beijing 100029, China \\ ${ }^{3}$ Chengdu Integrated TCM and Western Medicine Hospital, Chengdu 610016, China \\ ${ }^{4}$ Department of Science and Technology, Beijing University of Chinese Medicine, Beijing 100029, China \\ ${ }^{5}$ First School of Clinical Medicine, Shaanxi University of Chinese Medicine, Xianyang 712046, China
}

Correspondence should be addressed to Lili Wu; qingniao_566@163.com and Tonghua Liu; thliu@vip.163.com

Received 22 July 2021; Revised 22 August 2021; Accepted 25 August 2021; Published 3 September 2021

Academic Editor: Alessandra Durazzo

Copyright $\odot 2021$ You Wu et al. This is an open access article distributed under the Creative Commons Attribution License, which permits unrestricted use, distribution, and reproduction in any medium, provided the original work is properly cited.

\begin{abstract}
Background. Cinnamic acid (CA) has been shown to have many beneficial effects including regulating lipid metabolism and reducing obesity. However, its effect on nonalcoholic fatty liver disease (NAFDL) has not been investigated in detail. Thus, we performed this study in order to explore CA's effect on hepatic lipid metabolism and the underlying mechanisms. Method. Oleic acid (OA) was used to induce lipid accumulation in HepG2 cells. After coincubation with CA, the cells were stained with oil red O and the triglyceride (TG) content was assessed. Key genes in lipogenesis and fatty acid oxidation pathways were tested. Additionally, $\mathrm{db} / \mathrm{db}$ and $\mathrm{wt} / \mathrm{wt}$ mice were divided into three groups, with the wt/wt mice representing the normal group and the $\mathrm{db} /$ $\mathrm{db}$ mice being divided into the NAFLD and CA groups. After 4 weeks of oral treatment, all mice were sacrificed and the blood lipid profile and liver tissues were assessed. Results. CA treatment reduced the lipid accumulation in HepG2 cells and in db/db mouse livers. ACLY, ACC, FAS, SCD1, PPAR $\gamma$, and CD36 were significantly downregulated, while CPT1A, PGC1 $\alpha$, and PPAR $\alpha$ were significantly upregulated. Conclusion. CA's therapeutic effect on NAFLD may be attributed to its ability to lower hepatic lipid accumulation, which is mediated by suppression of hepatic lipogenesis and fatty acid intake, as well as increased fatty acid oxidation.
\end{abstract}

\section{Introduction}

Nonalcoholic fatty liver disease (NAFLD), the incidence of which often parallels the trends in obesity, type II diabetes, dyslipidemia, and other metabolic diseases, has become a major health problem worldwide and the most common chronic liver disease in recent years [1]. The global prevalence of NAFLD is approximately $25.24 \%$ [2] and the rate continues to increase [3]. NAFLD begins with simple hepatic steatosis and can develop into nonalcoholic steatohepatitis, potentially leading to hepatic fibrosis and cirrhosis and causing severe complications such as hepatocellular carcinoma [1]. It reflects disrupted body energy homeostasis, which is the common pathological change in metabolic diseases.

Intrahepatic triglyceride (IHTG) accumulation indicates imbalanced hepatic energy metabolism and it can be regarded as a biomarker of NAFLD $[4,5]$. Abnormally high IHTG levels in individuals with NAFLD may be attributed to increased de novo lipogenesis (DNL) and decreased fatty acid oxidation. Fatty acids are synthesized in the liver through DNL and are esterified by glycerol-3-phosphate to 
produce triglyceride (TG). DNL is mediated by several lipogenic enzymes, the transcription of which is governed by transcription factors such as carbohydrate-responsive element-binding protein (ChREBP), sterol regulatory elementbinding protein 1c (SREBP1c), and liver X receptors (LXRs) [6]. Fatty acid catabolism in the liver mainly takes place within mitochondria, generating ATP and ketone bodies. Long-chain fatty acid- (LCFA-) CoA translocates into mitochondria, which is mediated by carnitine palmitoyltransferase-1A (CPT1A), the rate-limiting enzyme for fatty acid $\beta$-oxidation [7]. Altered activity of the above pathways in individuals who consume excess calories results in NAFLD and other metabolic diseases [8]. Thus, regulating energy metabolism, especially the fatty acid synthesis and oxidation pathways in hepatocytes, plays an important role in controlling excess IHTG levels and, eventually, improves the condition of NAFLD.

Cinnamic acid (CA) is a natural polyphenol that comprises nine carbon atoms (C6-C3) (Figure 1(a)). It occurs in many fruits such as citrus fruits and grape and vegetables such as spinach and celery, and CA and its many derivatives are permitted to be used as flavor compounds in numerous regions by authorities $[9,10]$. However, it is mostly enriched in Cinnamomum cassia (Chinese cinnamon) [11, 12], which has been used as a traditional herb as well as a flavoring material in many countries for thousands of years [13]. It has been demonstrated that CA possesses multiple therapeutic effects, including antimicrobial [14], anticancer [15, 16], anti-inflammatory [17], antioxidant [18, 19], and antidiabetic [10] effects. Moreover, recent studies have highlighted CA's effects on lipid metabolism and obesity. It was reported that CA lowered the serum lipid levels in streptozotocin(STZ-) induced diabetic rats [20] and in animal models of high fat diet-induced obesity [21,22]. In vitro studies showed that CA stimulated white fat browning in 3T3-L1 adipocytes and activated HIB1B brown adipocytes [23]. It also lowered the TG levels in 3T3-L1 cells [24] and lipid accumulation in oleic acid- (OA-) treated HepG2 hepatocytes [22]. Moreover, in a previous study on a palmitic acid-induced triglyceride accumulation cell model, CA treatment elevated CPT1 protein expression, suggesting CA may accelerate lipid oxidation in vitro [25].

Although CA has exhibited hypolipidemic effects in both in vivo and in vitro experiments, the underlying mechanisms of CA's effect on NAFLD are still poorly understood. Thus, we investigated the effect of CA on OA-stimulated HepG2 cells and $\mathrm{db} / \mathrm{db}$ mice, a commonly used genetic model for NAFLD [26, 27], and we explored the alterations in the expression of transcription factors and key enzymes in the lipogenesis and fatty acid oxidation pathways in cells and mice after CA treatment.

\section{Materials and Methods}

2.1. Chemicals and Reagents. Cinnamic acid ( $\geq 99.5 \%$ purity) was purchased from Shanghai Yuanye (Shanghai, China). Dulbecco's modified eagle medium (DMEM), fetal bovine serum (FBS), and $0.25 \%$ trypsin-ethylenediaminetetraacetic acid (EDTA) were purchased from Gibco (Carlsbad, CA,
USA). OA was purchased from Sigma-Aldrich (St. Louis, MO, USA). Bovine serum albumin (BSA) and $0.5 \%$ carboxymethyl cellulose (CMC) sodium salt solution were purchased from Solarbio Science \& Technology (Beijing, China) and Coolaber Science \& Technology (Beijing, China), respectively. CA was dissolved in $0.5 \%$ CMC buffer solution before being orally administered to the mice.

2.2. Cell Culture. HepG2 cells were purchased from KeyGEN Biotech (Nanjing, China). The cells were cultured in DMEM with $10 \% \mathrm{FBS}$ and maintained in a humidified, $37^{\circ} \mathrm{C}$, $5 \% \mathrm{CO}_{2}$ environment, with the media changed every 24 hours. Based on previous studies, $0.5 \mathrm{mM} \mathrm{OA}$ was used to establish a high-fat model in vitro [28, 29]. After reaching $80 \%$ confluence, the cells were placed in 6-well plates and stimulated with $0.5 \mathrm{mM}$ OA media with or without CA of different concentrations. Cells cultured without OA were used as normal controls. The OA/BSA complex used for cell stimulation was prepared as follows: $\mathrm{OA}$ was dissolved in $0.1 \mathrm{M} \mathrm{NaOH}$ and heated at $70^{\circ} \mathrm{C}$ for $30 \mathrm{~min}$ to form a $100 \mathrm{mM}$ OA solution. This was further mixed with $10 \%$ BSA in phosphate-buffered saline to acquire a $10 \mathrm{mM}$ OA/BSA complex. This complex was diluted in DMEM with 10\% FBS to a concentration of $0.5 \mathrm{mM}$ for final use. All cell experiments were performed in at least three replicate wells.

2.3. Cell Viability Assay. The effect of CA on the viability of HepG2 cells was assessed by Cell Counting Kit- (CCK-) 8 assays. CCK- 8 assays were conducted as previously described $[22,30]$ with slight modification. Briefly, $200 \mu \mathrm{l}$ HepG2 cells were seeded at a density of $1 \times 10^{4} /$ well in a 96well plate and cultured for $12 \mathrm{~h}$. Thereafter, the cells were treated with CA (diluted to $12.5,25,50,100$, or $200 \mu \mathrm{M}$ ) for $24 \mathrm{~h}$, followed by changing the media to $200 \mu \mathrm{L}$ DMEM containing $10 \mu \mathrm{L}$ CCK-8 solution (Dojindo Molecular Technologies, Kumamoto, Japan) and incubating for $1 \mathrm{~h}$ in $37^{\circ} \mathrm{C}$. Absorbance at $450 \mathrm{~nm}$ was measured using a microplate reader (Promega BioSystems Sunnyvale, Sunnyvale, CA, USA). Cells cultured in DMEM with 10\% FBS (without $\mathrm{CA}$ ) were used as normal controls.

2.4. Oil Red O Staining and TG Assessment. After treatment for $24 \mathrm{~h}$, HepG2 cells were stained with Oil red O to determine the intracellular lipid accumulation. The staining was performed using a commercial kit (Solarbio Science \& Technology) according to the manufacturer's instructions. TG content of HepG2 cells was determined using a TG measuring kit (Nanjing Jiancheng Bioengineering, Nanjing, China) following the manufacturer's instructions. Cells cultured in DMEM with 10\% FBS were used as normal controls.

2.5. Animal Experiments. The animal experiments conducted in this study were approved by the Animal Care and Ethics Committee of Beijing University of Traditional Chinese Medicine (approval no. BUCM-4-20190931002-1088). A total number of 145 -week-old male C57BL/KsJ-db/db mice and 7 


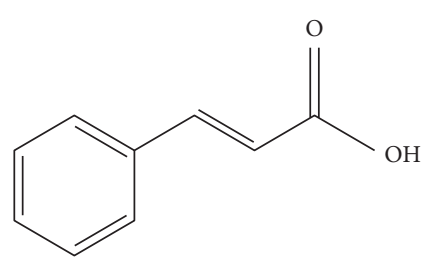

(a)
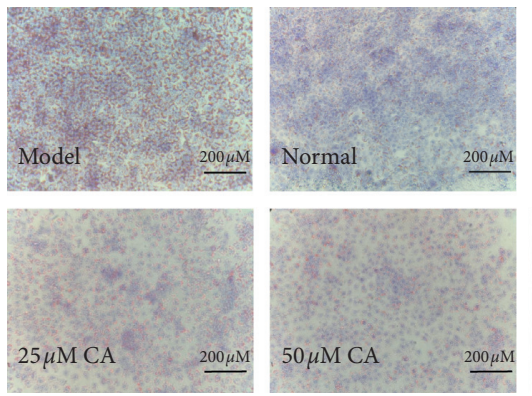

(c)
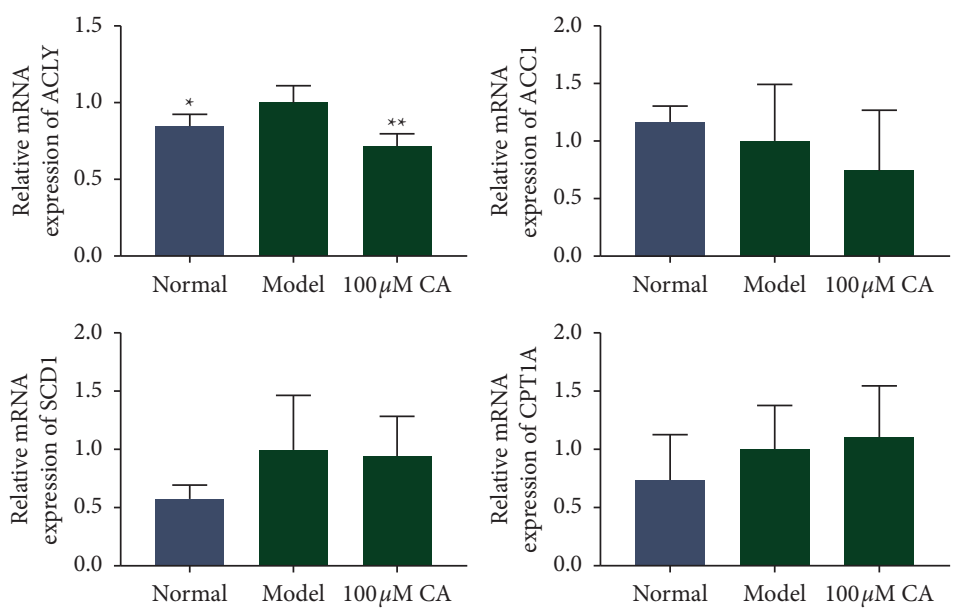

(e)

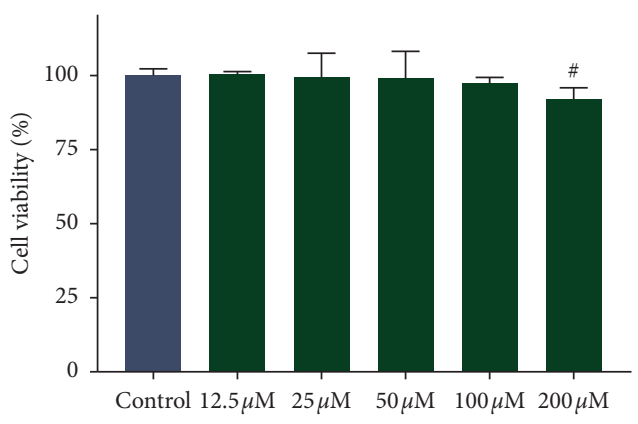

(b)

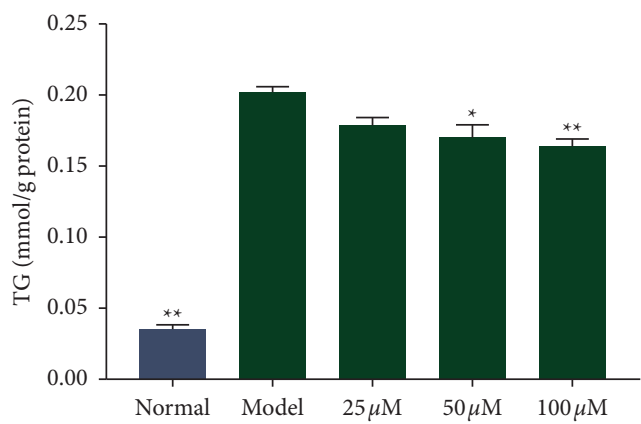

(d)
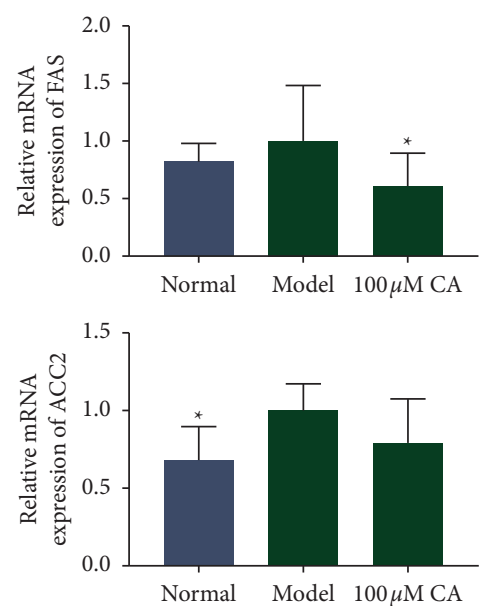

FIgURE 1: (a) Chemical structure of cinnamic acid (CA). (b) CCK-8 assay results. Control group: HepG2 cells cultured with 10\% FBS in DMEM. $25 \mu \mathrm{M}$ group: cells cultured with $25 \mu \mathrm{M}$ CA, $10 \%$ FBS in DMEM. $50 \mu \mathrm{M}$ group: cells cultured with $50 \mu \mathrm{M}$ CA, $10 \%$ FBS in DMEM. $100 \mu \mathrm{M}$ group: cells cultured with $100 \mu \mathrm{M}$ CA, 10\% FBS in DMEM. $200 \mu \mathrm{M}$ group: cells cultured with $200 \mu \mathrm{M}$ CA, $10 \%$ FBS in DMEM. (c) Images of oil red O staining of HepG2 cells (200X magnification). (d) Triglyceride (TG) content of HepG2 cells after treatment for $24 \mathrm{~h}$. (e) mRNA expression of ATP-citrate lyase (ACLY), acetyl-CoA carboxylase 1 (ACC1), fatty acid synthase (FAS), and stearoyl-CoA desaturase 1 (SCD1), carnitine palmitoyltransferase-1A (CPT1A), and ACC2 in HepG2 cells. Normal group: cells cultured with 10\% FBS in DMEM. Model group: cells cultured with $0.5 \mathrm{mM}$ oleic acid (OA). $25 \mu \mathrm{M}$ group: cells cultured with $0.5 \mathrm{mM}$ OA and $25 \mu \mathrm{M}$ CA. $50 \mu \mathrm{M}$ group: cells cultured with $0.5 \mathrm{mM} \mathrm{OA}$ and $50 \mu \mathrm{M}$ CA. $100 \mu \mathrm{M}$ group: cells cultured with $0.5 \mathrm{mM} \mathrm{OA}$ and $100 \mu \mathrm{M}$ CA. Data are presented as mean $\pm \mathrm{SD},{ }^{*} p<0.05,{ }^{* *} p<0.01$, compared to the model group; ${ }^{*} p<0.05$, compared to control group.

age-matched male C57 BL/KsJ-wt/wt mice were purchased from Nanjing Biomedical Research Institute of Nanjing University (Nanjing, China) and housed in specific-pathogen-free conditions under a 12/12 h light/dark cycle, with free access to water and food. The bodyweight of mice was measured every week. After 1 week of acclimatization, all mice were fasted overnight and blood glucose was measured by a portable glucometer (Glucocard 01-mini;
Arkray, Kyoto, Japan) using blood collected from the tail vein.

The $\mathrm{db} / \mathrm{db}$ mice were then randomly divided into two groups with fasting blood glucose and body weight of which at the same baseline: the CA and NAFLD groups. The CA mice were orally treated with $20 \mathrm{mg} / \mathrm{kg}$ body weight CA every day. The dosage was chosen based on previous studies. The NAFLD model mice were treated with the same volume 
of the vehicle (0.5\% CMC buffer). The wt/wt mice were used as the normal control group and treated the same as NAFLD mice. After 4 weeks of treatment, the mice were sacrificed. Blood samples were collected and centrifuged to acquire serum. Additionally, liver and epididymal adipose tissues were removed and weighed. A small slice of each tissue was fixed in $4 \%$ paraformaldehyde solution (Solarbio Science \& Technology) and the remaining tissues were immediately frozen in liquid nitrogen.

2.6. Assessment of Serum Lipid Profile and IHTG. The serum was stored at $-20^{\circ} \mathrm{C}$ before the total cholesterol (TC), TG, high-density lipoprotein (HDL), low-density lipoprotein (LDL), free fatty acid (FFA), and glucose levels were tested using an automated chemistry analyzer (AU480; Beckman Coulter, Brea, CA, USA). IHTG levels (mmol/g protein) of the mice were measured using a commercial kit (Nanjing Jiancheng Bioengineering, Nanjing, China).

2.7. Histological Analysis of Liver and Adipose Tissues. Liver tissues and epididymal adipose tissues fixed in $4 \%$ paraformaldehyde were embedded in paraffin, cut into $4 \mu \mathrm{m}$ thick slices using a microtome, and then stained with hematoxylin and eosin (H\&E). Immunohistochemical (IHC) staining of liver tissues was used to examine protein expression. Primary antibodies against SREBP1 (ab191857; Abcam, Cambridge, UK) and CPT1A (ab234111; Abcam) were used, followed by incubation with horseradish peroxidase- (HRP-) labeled anti-rabbit IgG secondary antibody for $20 \mathrm{~min}$. The tissues were then stained with $3,3^{\prime}$-diaminobenzidine (DAB) and counterstained with hematoxylin. The IHC staining images were analyzed based on the mean optical density using ImageJ software (National Institutes of Health, Bethesda, MD, USA).

2.8. Quantitative Real-Time PCR (RT-qPCR). Total RNA was extracted from HepG2 cells and the liver tissues using a commercial kit (Tiangen Biotech, Beijing, China) according to the manufacturer's instructions. The RNA was then homogenized by RNase-free water to the same concentration of $0.5 \mathrm{ng} /$ tube and cDNA was synthesized using a PrimeScript ${ }^{\mathrm{TM}}$ RT Reagent Kit with gDNA Eraser (Takara Bio, Kusatsu, Japan). Thereafter, the RT-qPCR analyses were conducted on Applied Biosystems 7500 Real-Time PCR system (Thermo Fisher Scientific, Waltham, MA, USA) using a GoTaq ${ }^{\circledR}$ qCR Master Mix Kit (Promega). The expression levels of target genes were normalized to glyceraldehyde 3-phosphate dehydrogenase (GAPDH) and the results were calculated using the relative quantitative $\left(2^{-\Delta \Delta \mathrm{CT}}\right)$ method. The primers used are listed in Table 1.

2.9. Western Blot Analysis. Total protein was extracted from the liver tissues as follows. The tissues were homogenized and lysed using radioimmunoprecipitation assay (RIPA) lysis buffer containing protease inhibitor, phosphatase inhibitor, and phenylmethanesulfonyl fluoride (KeyGEN Biotech). The concentration of each extracted protein solution was then measured using a Bradford protein quantitative assay with Coomassie brilliant blue G-250 (Solarbio Science \& Technology). Protein samples were prepared at a concentration of $1 \mu \mathrm{g} /$ $\mu \mathrm{l}$ and denatured at $100^{\circ} \mathrm{C}$ for $5 \mathrm{~min}$ in loading buffer (Solarbio Science \& Technology). The proteins were loaded onto $10 \%$ sodium dodecyl sulfate-polyacrylamide gel electrophoresis (SDS-PAGE) gels and separated according to their molecular weights. They were then transferred onto methanol-soaked $0.45 \mu \mathrm{m}$ polyvinylidene fluoride membranes (Millipore, Bedford, MA, USA). These membranes were then blocked using Blocking-One solution (Nacalai Tesque, Kyoto, Japan) for $1 \mathrm{~h}$ and then incubated with primary antibodies against the following proteins: ATP-citrate lyase (ACLY; \#13390; Cell Signaling Technology, USA), acetyl-CoA carboxylase (ACC; \#3676; Cell Signaling Technology), fatty acid synthase (FAS; \#3180; Cell Signaling Technology), stearoyl-CoA desaturase 1 (SCD1; \#2794; Cell Signaling Technology), CPT1A (ab234111; Abcam), and $\beta$-actin (\#4970; Cell Signaling Technology) at $4^{\circ} \mathrm{C}$ overnight. After washing with Tris-buffered saline with Tween 20 (TBST; Beijing Applygen Technologies, Beijing, China), the membranes were incubated with HRP-conjugated AffiniPure goat anti-rabbit IgG secondary antibody (Proteintech Group, Rosemont, IL, USA) for $1 \mathrm{~h}$ and washed with TBST again. Enhanced chemiluminescence (ECL) reagent (Solarbio Science \& Technology) was reacted with the HRP to generate fluorescence. The gray values of the protein bands were calculated by normalization to the endogenous control protein $\beta$-actin.

2.10. Statistical Analysis. All data are presented as mean\pm standard deviation (SD). SPSS 23.0 software (SPSS, Chicago, IL, USA) was used for statistical analysis. Normally distributed data were compared between two groups using Student's $t$-test. Normally distributed data were compared between three or more groups using one-way analysis of variance (ANOVA) followed by the least significant difference (LSD) test for groups with equal variances or Dunnett's test for groups with unequal variances. Nonnormally distributed data were compared between two groups using the Mann-Whitney $U$ test. Nonnormally distributed data were compared between three or more groups using the nonparametric Kruskal-Wallis test. A statistically significant difference was defined as $p<0.05$ or $p<0.01$.

\section{Results}

3.1. Effect of CA on HepG2 Cell Viability. CA treatment at doses of $12.5,25,50$, or $100 \mu \mathrm{M}$ for $24 \mathrm{~h}$ had no significant impact on the viability of HepG2 cells (Figure 1(b)). The viability of the cells in the $200 \mu \mathrm{M}$ CA group was lower than that of the control group $(p<0.05)$. Therefore, 25,50 , and $100 \mu \mathrm{M}$ CA were chosen for further investigations.

3.2. Effect of CA on Lipid Accumulation in HepG2 Cells. Oil red $\mathrm{O}$ staining showed that $\mathrm{OA}$ dramatically increased the lipid accumulation in HepG2 cells and CA treatment ameliorated this increase. The lipid droplets were remarkably reduced in the CA group compared to the NAFLD 
TABLE 1: Sequences of primers used in RT-qPCR.

\begin{tabular}{lcc}
\hline Gene & Forward primer & Reverse primer \\
\hline ACC1 & GATGAACCATCTCCGTTGGC & GACCCAATTATGAATCGGGAGTG \\
ACC2 & CGCTCACCAACAGTAAGGTGG & GATGGCAGGGAGTTCCTC \\
ACLY & ACCCTTTCACTGGGGATCACA & GAGGCGAACTGAGGGCTTC \\
BDK & ACATCAGCCACCGATACACAC \\
CD36 & ATGGGCTGTGATCGGAACTG & GTCTTCCCAATAAGCATGTCTCC \\
ChREBP & GAACCGCCTCTTCTGCT & CAACTCCATACAACCCTCG \\
CPT1A & AGATCAATCGGACCCTAGACAC \\
FAS & GGAGGTGGTGATAGCCGGTAT & CAGCGAGTAGCGCATAGTCA \\
GAPDH & AAGATGGTGAAGGTCGGTGT & TGGGTAATCCATAGAGCCCAG \\
LXR $\alpha$ & GCTTCCCATTCTCAGCCTTG \\
PGC1 $\alpha$ & CTCAATGCCTGATGTTTCTCCT & TCCAACCCTATCCCTAAAGCAA \\
PPAR $\alpha$ & TTCAAGATCCTGTTACTACT & ACCTTGAACGTGATCTCACA \\
PPAR $\gamma$ & ACGCGAGTTCCTTAAGAACCTG & GTGTCATCTGGATGGTTGCTCT \\
PPM1K & GGAAGACCACTCGCATTCCTT & GTAATCAGCAACCATTGGGTCA \\
SCD1 & TTATCAGCGGCCTTCATTACTTT & GGATGGAGCTTAACAACACTCTC \\
SREBP1c & TTCTTGCGATACACTCTGGTGC & CGGGATTGAATGTTCTTGTCGT \\
GAPDH (human) & CAAGAAGCGGATGTAGTCG & GAGCCGTGGTGAGAAGC \\
ACC1 (human) & GGAGCGAGATCCCTCCAAAAT & GGCTGTTGTCATACTTCTCATGG \\
ACC2 (human) & ATGTCTGGCTTGCACCTAGTA & CCCCAAAGCGAGTAACAAATTCT \\
CPT1 (human) & CCCTGAGTTATCAGAGGCTGG \\
FAS (human) & TCGGCCGATCACCAAGAGTAAA & CGAGCATACTTGAACCGATTCT \\
SCD1 (human) & TCCAGTTGGCTTATCGTGGTG & TGGCTTCATAGGTGACTTCCA \\
\hline & AAGGACCTGTCTAGGTTTGATGC & TCGTCTCCAACTTATCTCCTCC \\
\hline
\end{tabular}

group (Figure 1(c)). This was further confirmed by the results of the TG content examination. The TG content was significantly increased by $\mathrm{OA}$, and $\mathrm{CA}$ reduced the TG content in a dose-dependent manner (Figure 1(d)). qPCR results indicated that CA treatment significantly suppressed the expression of ACLY and FAS. It also showed the tendency to decrease the expression of ACC1, ACC2, and SCD1 and increase the expression of CPT1A (statistically insignificant, Figure 1(e)).

3.3. Effect of CA on Body Weight, Blood Glucose, and Liver and Fat Mass of $d b / d b$ Mice. Mice in the CA group were lighter after 4 weeks than those in the NAFLD group (Figures 2(a) and 2(b)). Oral administration of CA significantly reduced body weight gain of $\mathrm{db} / \mathrm{db}$ mice from the third week. Notably, CA decreased the liver mass and liver index (liver mass/body weight) in the obese $\mathrm{db} / \mathrm{db}$ mice ( $p<0.05$ and $p<0.01$, respectively) (Figures $2(\mathrm{c})$ and $2(\mathrm{~d})$ ). CA also exhibited a hypoglycemic effect in the $\mathrm{db} / \mathrm{db}$ mice, as at the end of the treatment, the glucose levels in CA group were significantly lower than those in the NAFLD group despite the same baseline (Figure 2(e)), confirming its previously reported antidiabetic effect $[31,32]$. Furthermore, CA reduced the mean weight of epididymal fat, though the data was not significant according to one-way ANOVA (Figure 2(f)).

3.4. Effect of CA on Serum Lipid Profile and IHTG Levels in db/ $\mathrm{db}$ Mice. The serum TG, IHTG, and FFA levels in $\mathrm{db} / \mathrm{db}$ mice were significantly lowered and the HDL level was raised by CA treatment (Figures 3(b), 3(c), 3(e), and 3(f)), suggesting that $\mathrm{CA}$ improved lipid metabolism and may have a beneficial effect on NAFLD. However, CA had no noticeable effect on serum TC or LDL levels (Figures 3(a) and 3(d)).

3.5. Histological Observation Results. The liver tissues and epididymal adipose tissues were fixed in paraffin and stained with $\mathrm{H} \& \mathrm{E}$ for observation of histological changes. Compared to normal wt/wt mice, $\mathrm{db} / \mathrm{db}$ mice in the NAFLD group had severe hepatic steatosis and disruption of hepatocyte structure (Figure 4(a)). These changes were ameliorated by CA treatment. Adipocytes in the NAFLD group were dramatically larger than those in the normal control group, consistent with the abovementioned increased epididymal fat mass. H\&E staining showed that 4 weeks of CA treatment reduced the size of the adipocytes (Figure 4(b)). The IHC analysis showed less SREBP1c-positive staining in the CA group than the NAFLD group (Figure $4(\mathrm{c})$ ). In contrast, the CPT1A-positive area was larger in the CA group than the NAFLD group (Figure $4(\mathrm{~d})$ ). The IHC results were further quantified and verified based on mean optical density using ImageJ software (Figure 4(e)).

3.6. CA Downregulated Lipogenesis Transcription Factors and Lipogenic Enzymes in $d b / d b$ Mice. The relative mRNA expression of transcription factors that regulate genes that encode lipogenic enzymes was downregulated and, consistently, the mRNA and protein expression of lipogenic enzymes including ACLY, ACC, FAS, and SCD1 were decreased (Figure 5). The mRNA expression of factors related to the expression and regulation of transcription factors, such as branched-chain ketoacid dehydrogenase kinase (BDK) and branched-chain ketoacid dehydrogenase phosphatase $(\mathrm{PPM} 1 \mathrm{~K})$, was also investigated by $\mathrm{qPCR}$. 


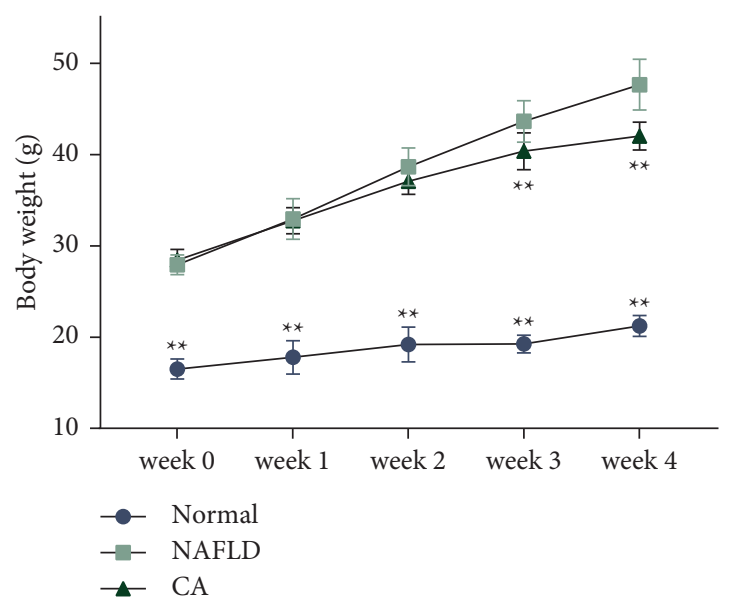

(a)

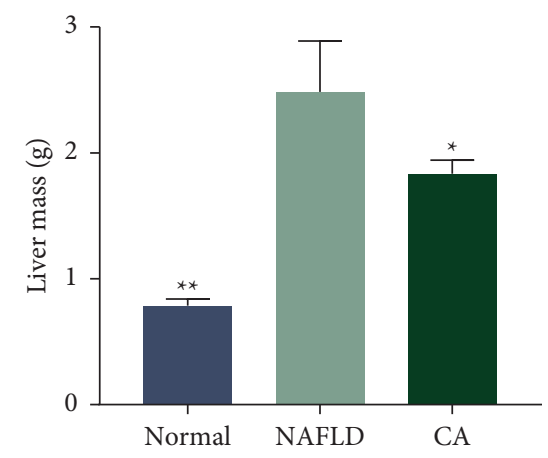

(c)

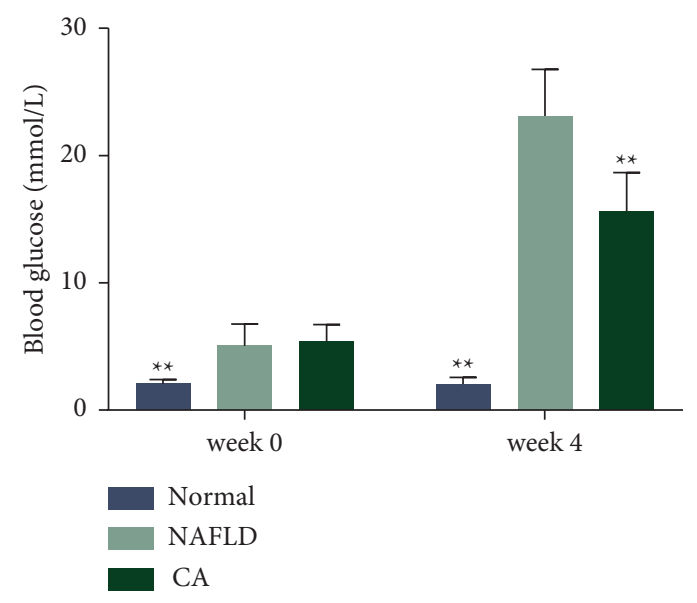

(e)

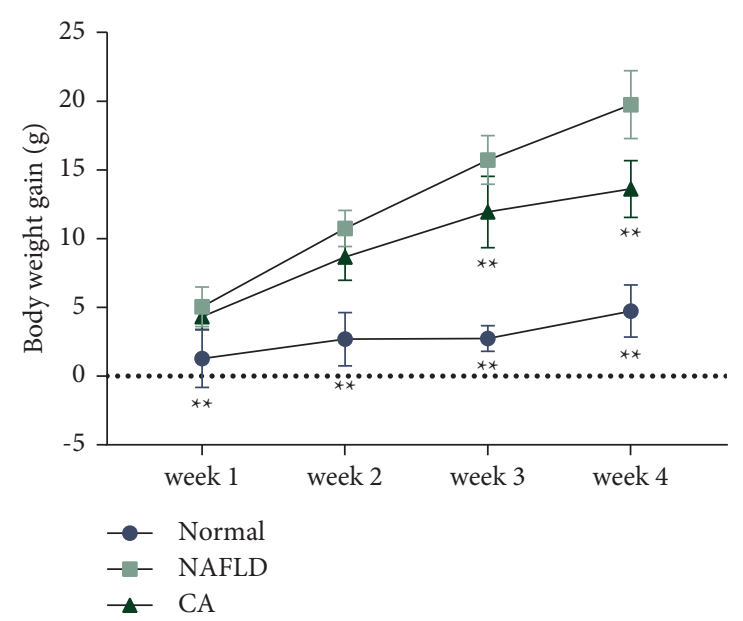

(b)

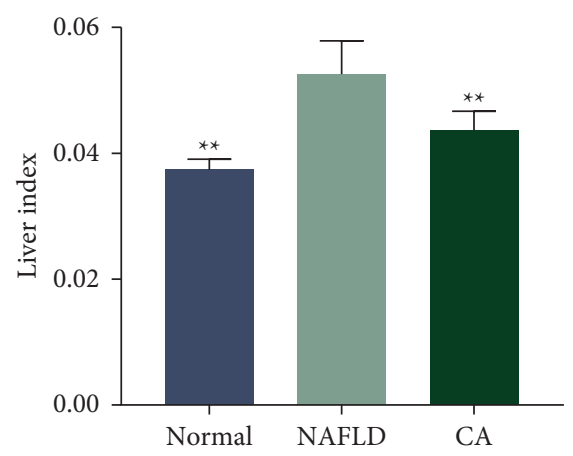

(d)

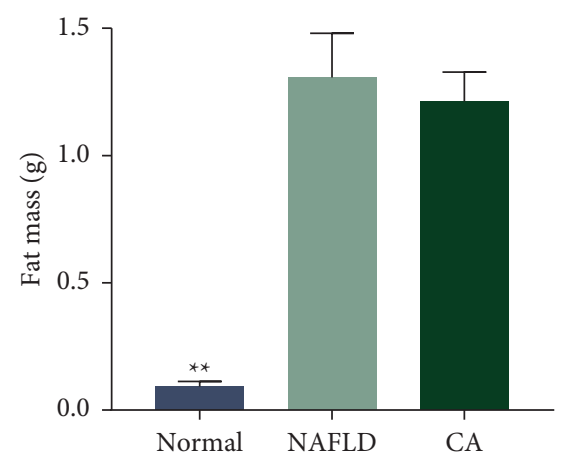

Figure 2: Cinnamic acid (CA) reduced body weight gain of $\mathrm{db} / \mathrm{db}$ mice, liver mass, liver index, and blood glucose levels. (a) Body weight of mice compared among groups of mice. (b) Body weight gain of mice compared to initial body weight at week 0. (c) Liver mass of mice. (d) Liver index (liver mass/body weight) of mice. (e) Blood glucose levels from week 0 (tested by portable glucose monitor using blood from tail vein) and week 4 (tested by automated chemistry analyzer using blood collected from abdominal aorta). (f) Epididymal fat (from the left side of mice) mass. Normal group: wt/wt mice treated with vehicle. NAFLD group: db/db mice treated with vehicle. CA group: $\mathrm{db} / \mathrm{db}$ mice treated with CA $20 \mathrm{mg} / \mathrm{kg} /$ day. Data are presented as mean $\pm \mathrm{SD} .{ }^{*} p<0.05,{ }^{* *} p<0.01$, compared to the model group. 


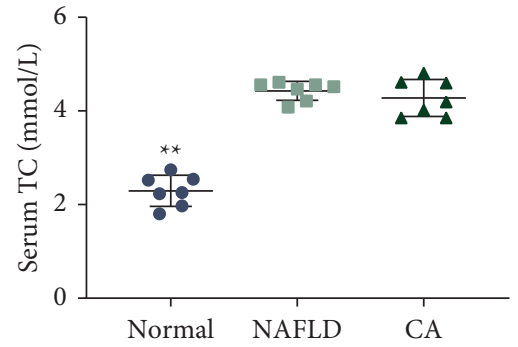

(a)

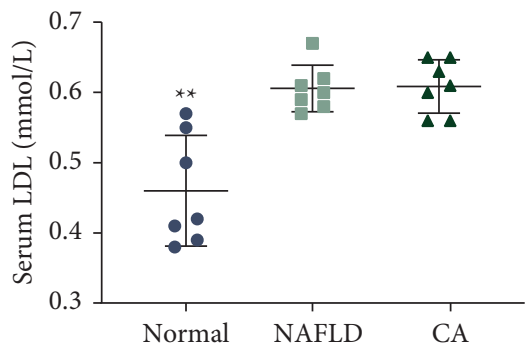

(d)

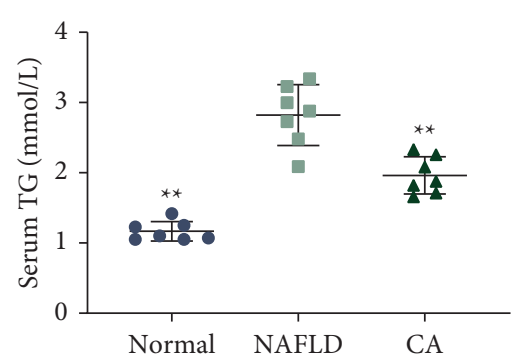

(b)

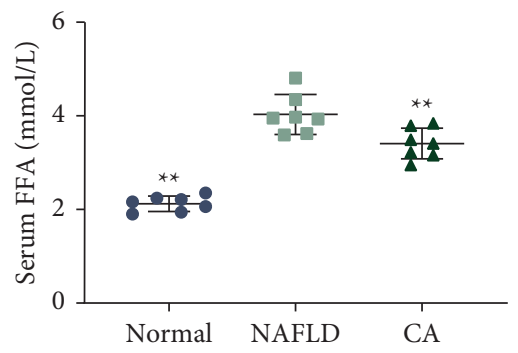

(e)

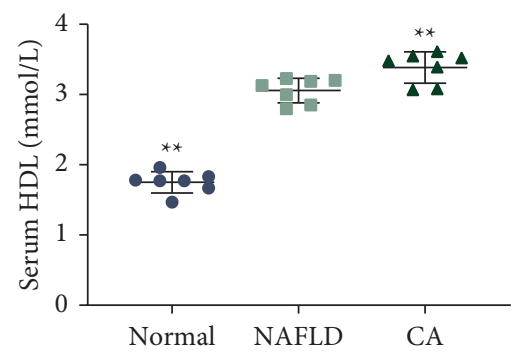

(c)

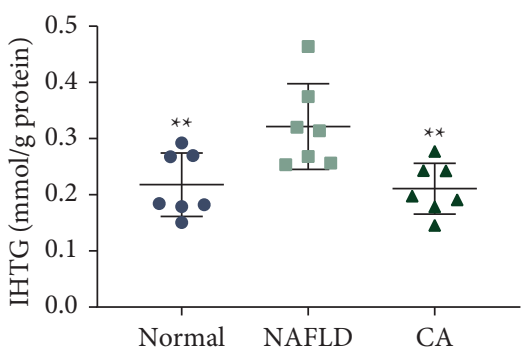

(f)

FIGURE 3: Serum lipid profile and intrahepatic triglyceride (IHTG) levels in mice. Serum total cholesterol (TC) levels (a), serum triglyceride (TG) levels (b), serum high-density lipoprotein (HDL) levels (c), serum low-density lipoprotein (LDL) levels (d), serum-free fatty acid (FFA) levels (e), and IHTG levels (f) in mice. Normal group: wt/wt mice treated with vehicle. NAFLD group: $\mathrm{db} / \mathrm{db}$ mice treated with vehicle. CA group: $\mathrm{db} / \mathrm{db}$ mice treated with CA $20 \mathrm{mg} / \mathrm{kg} /$ day. Data are presented as mean $\pm \mathrm{SD},{ }^{*} p<0.05,{ }^{* *} p<0.01$, compared to the NAFLD group.
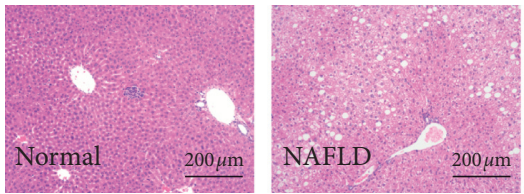

(a)
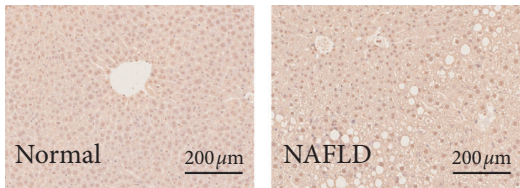

(c)
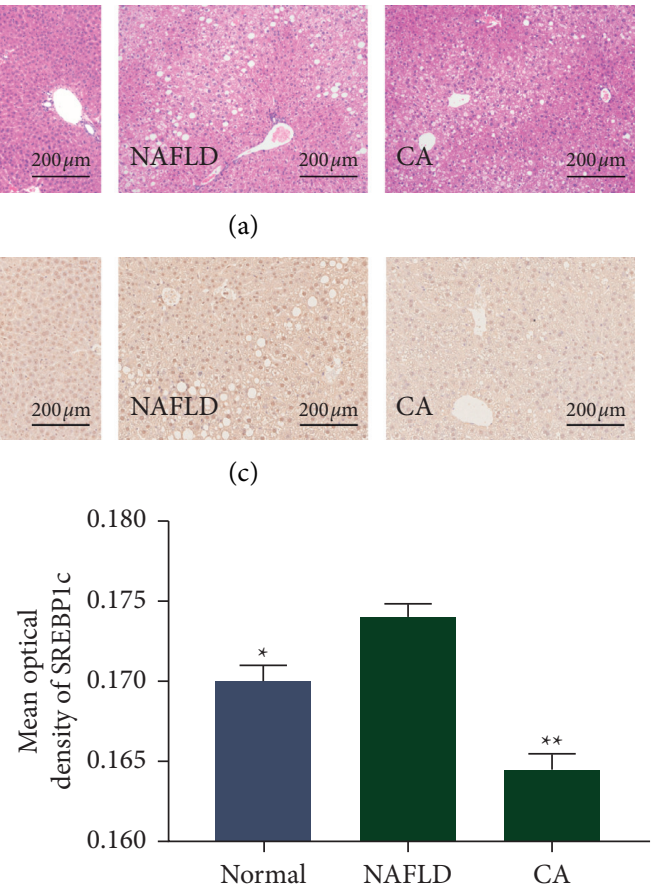

(e)
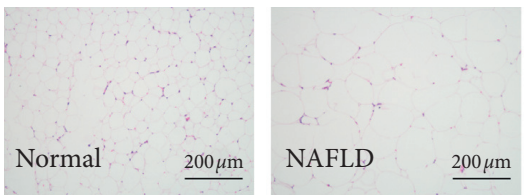

(b)
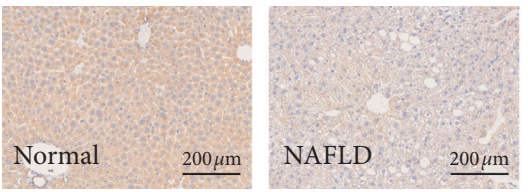

(d)

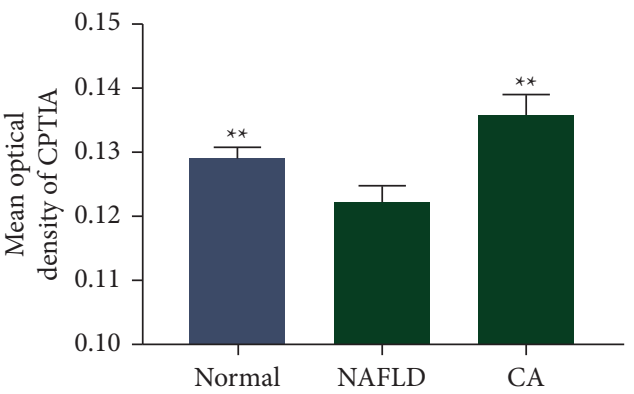

FIGURE 4: Histological observation results (200× magnification). (a) Images of H\&E staining of liver tissues. (b) Images of H\&E staining of epididymal fat tissues. (c) Immunohistochemical (IHC) staining of hepatic sterol regulatory element-binding protein 1c (SREPB1c) in mice. (d) IHC staining of hepatic carnitine palmitoyltransferase-1A (CPT1A) in mice. (e) Mean optical density of IHC staining images. Normal group: wt/wt mice treated with vehicle. NAFLD group: $\mathrm{db} / \mathrm{db}$ mice treated with vehicle. CA group: $\mathrm{db} / \mathrm{db}$ mice treated with CA $20 \mathrm{mg} / \mathrm{kg} /$ day. Data are presented as mean \pm SD. ${ }^{*} p<0.05,{ }^{* *} p<0.01$, compared to the NAFLD group. 

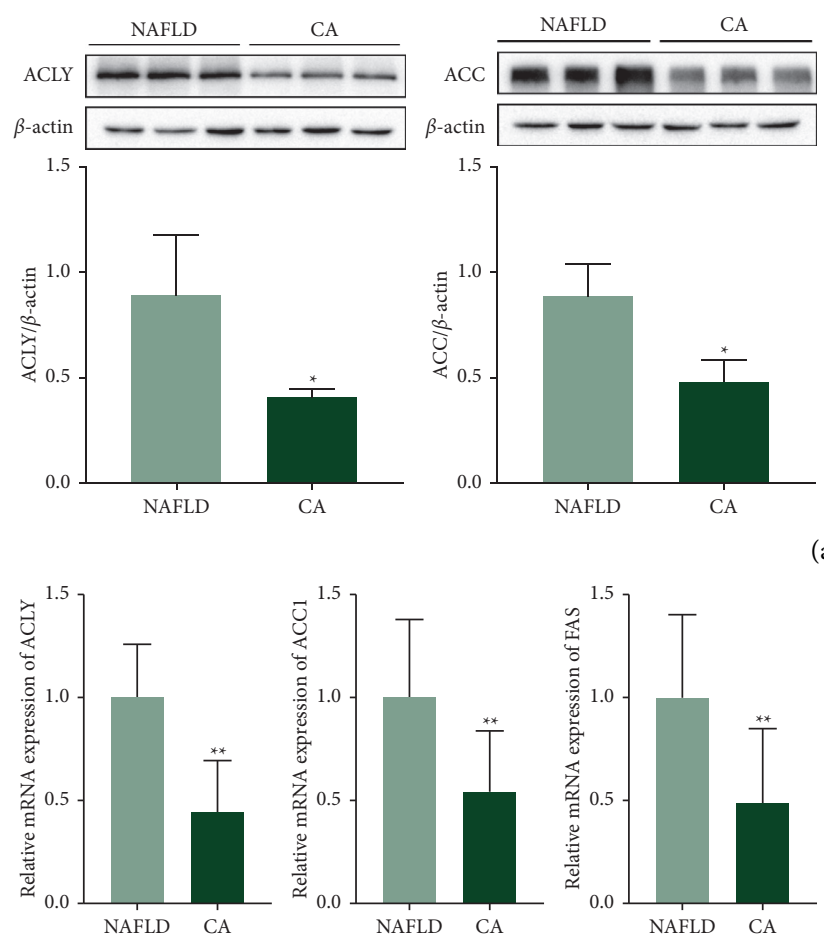

(a)
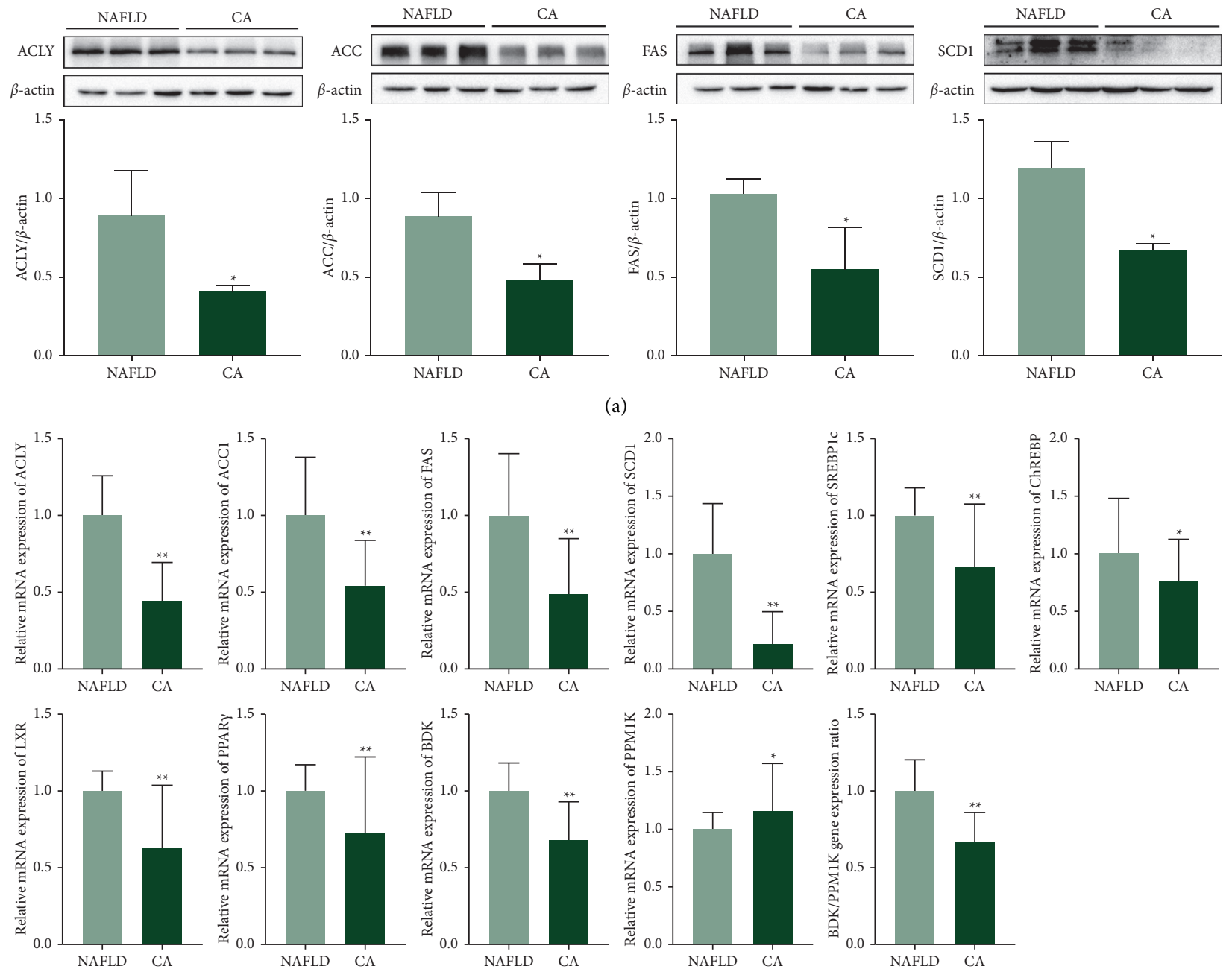

(b)

Figure 5: Cinnamic acid (CA) downregulated lipogenic transcription factors and other lipogenic genes in db/db mice. (a) Protein expression of ATP-citrate lyase (ACLY), acetyl-CoA carboxylase (ACC), fatty acid synthase (FAS), and stearoyl-CoA desaturase 1 (SCD1) in $\mathrm{db} / \mathrm{db}$ mice assessed by western blotting. (b) mRNA expression of ACLY, ACC1, FAS, SCD1, sterol regulatory element-binding protein 1c (SREBP1c), carbohydrate-responsive element-binding protein (ChREBP), liver X receptor $\alpha$ (LXR $\alpha$ ), peroxisome proliferator-activated receptor $\gamma(\operatorname{PPAR} \gamma)$, branched-chain ketoacid dehydrogenase kinase (BDK), and branched-chain ketoacid dehydrogenase phosphatase (PPM1K) in $\mathrm{db} / \mathrm{db}$ mice assessed by qPCR. NAFLD group: $\mathrm{db} / \mathrm{db}$ mice treated with vehicle. CA group: $\mathrm{db} / \mathrm{db}$ mice treated with CA $20 \mathrm{mg} /$ $\mathrm{kg} /$ day. Data are presented as mean $\pm \mathrm{SD}, n=3$ for western blotting analyses, $n=5$ for PCR analyses. ${ }^{*} p<0.05$, ${ }^{* *} p<0.01$, compared to the NAFLD group.

Moreover, BDK and PPM1K mRNA expression was decreased and increased by CA, respectively. This led to a significantly decreased BDK: PPM1K in the CA group.

3.7. CA Upregulated Fatty Acid Oxidation Pathway in $d b / d b$ Mice. Compared to the NAFLD group, mice in the CA group had higher CPT1A protein expression, which indicates that fatty acid oxidation was upregulated in the CA group. Additional factors from fatty acid metabolism pathways were also examined by qPCR. The results showed that CA increased the mRNA expression of peroxisome proliferator-activated receptor $\alpha(\operatorname{PPAR} \alpha)$ and peroxisome proliferator-activated receptor- $\gamma$ coactivator $1 \alpha(\mathrm{PGC} 1 \alpha)$ and decreased the mRNA expression of ACC2 and CD36 (Figure 6).

\section{Discussion}

As the most common chronic liver disease, NAFLD affects nearly one-third of the adult population and $10 \%$ of children in developed countries, and the prevalence continues to increase in concert with the increasing number of obese individuals [33, 34]. In Asian countries, the current prevalence of NAFLD is around $25 \%$, which is also increasing [35]. Unhealthy lifestyles, especially overconsumption of high-calorie foods and sedentary lifestyles and lack of exercise, lead to disorders of energy metabolism, causing 


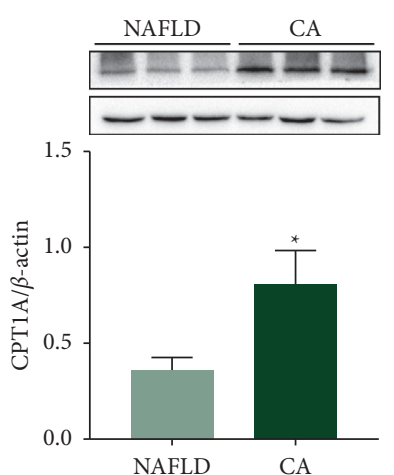

(a)
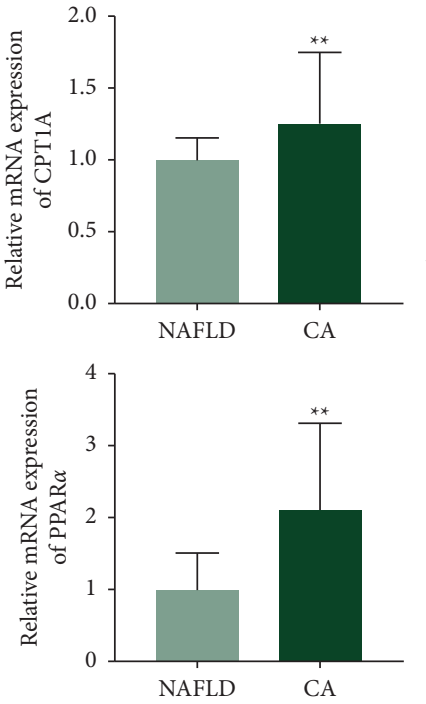
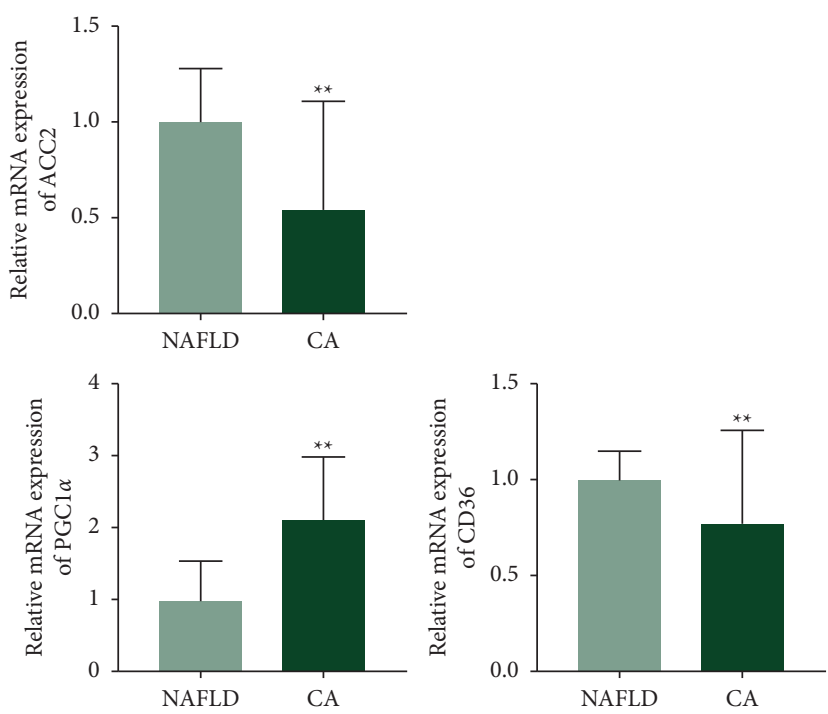

(b)

Figure 6: CA upregulated the fatty acid oxidation pathway and reduced CD36 mRNA expression in db/db mice. (a) Protein expression of carnitine palmitoyltransferase-1A (CPT1A) in $\mathrm{db} / \mathrm{db}$ mice assessed by western blotting. (b) mRNA expression of CPT1A, acetyl-CoA carboxylase 2 (ACC2), peroxisome proliferator-activated receptor $\alpha(\operatorname{PPAR} \alpha)$, peroxisome proliferator-activated receptor- $\gamma$ coactivator $1 \alpha$ (PGC1 $\alpha$ ), and CD36 in db/db mice assessed by qPCR. NAFLD group: $\mathrm{db} / \mathrm{db}$ mice treated with vehicle. CA group: db/db mice treated with CA $20 \mathrm{mg} / \mathrm{kg} /$ day. Data are presented as mean $\pm \mathrm{SD}, n=3$, for western blotting analyses, $n=5$ for PCR analyses. ${ }^{*} p<0.05$, ${ }^{* *} p<0.01$, compared to the NAFLD group.

dyslipidemia, obesity, metabolic syndrome, and type 2 diabetes [36].

CA, a chemical almost ubiquitous in plants and particularly enriched in cinnamon, has been reported to improve lipid metabolism and ameliorate diabetes and obesity [20, 21, 23, 31, 32, 37-39]. Despite recent research progress, CA's effects on NAFLD and the possible mechanisms remain to be elucidated. The development of NAFLD is linked to the abnormal accumulation of hepatic lipids, manifested as an excessive level of IHTG [33]. In our study, CA treatment significantly decreased OA-induced lipid accumulation in HepG2 cells and significantly reduced the TG content in a dose-dependent manner. In $\mathrm{db} / \mathrm{db}$ mice, 4 weeks of CA treatment at $20 \mathrm{mg} / \mathrm{kg} / \mathrm{day}$ significantly decreased body weight gain and the blood glucose level of $\mathrm{db} / \mathrm{db}$ mice. CA treatment also improved the serum lipid profile of $\mathrm{db} / \mathrm{db}$ mice, as indicated by lower FFA and TG levels compared to those in the NAFLD group. Most importantly, the liver weight and liver index, as well as the IHTG levels, were significantly decreased, showing that CA treatment exerted effects against NAFLD in vivo.

As the increased IHTG is caused by increased DNL and fatty acid uptake rates (TG synthesis) and a lower fatty acid oxidation rate (TG break down), we investigated the effect of CA on the lipogenesis and fatty acid oxidation pathways. Aiming to explore the underlying mechanisms of the effects of CA on NAFLD model animals, only the NAFLD group and CA group were included in our PCR and western blotting analyses, as comparing the differently expressed factors within these two groups would be sufficient for the demonstration.
Abundant carbohydrates are converted into fatty acids and then esterified to form TGs in the liver and adipose tissues via DNL [40]. DNL in the liver is mediated by a series of coordinated lipogenic enzymes [41]. Briefly, citrate, which is generated from glucose via glycolysis and the tricarboxylic acid cycle, is transformed by ACLY into acetyl-CoA. AcetylCoA from the first step of DNL is carboxylated by ACC to form malonyl-CoA. Mammals have two types of ACC proteins, ACC1 in the cytoplasm and ACC2 on the mitochondrial outer membrane [42]. Malonyl-CoA is believed to inhibit CPT1A, and suppression of ACC1 and ACC2 decreases the hepatic malonyl-CoA levels, increases fatty acid oxidation, and improves NAFLD in diet-induced rat models $[43,44]$. Malonyl-CoA is further converted into palmitic acid by FAS. Palmitic acid is elongated on the endoplasmic reticulum to form LCFAs, which are subsequently desaturated by SCD1 to generate unsaturated fatty acids. Palmitic acid, LCFAs, and unsaturated fatty acids are all fatty acid products of DNL, and they can be esterified to generate IHTG $[40,44,45]$. In this study, CA downregulated the mRNA expression of the lipogenesis genes ACLY, ACC, FAS, and SCD1, suggesting that CA suppresses fatty acid synthesis in vivo. The western blotting results showed that CA also significantly decreased the related protein expression. As an in vitro model of human liver steatosis, OAinduced lipid accumulation was suppressed by CA in HepG2 cells. The results showed that $100 \mu \mathrm{M}$ of CA significantly downregulated several key genes' expression levels in lipogenesis.

The genes encoding lipogenesis proteins are primarily governed by transcription factors [6]. SREBP1c binds to sterol regulatory elements, ChREBP binds to carbohydrate 


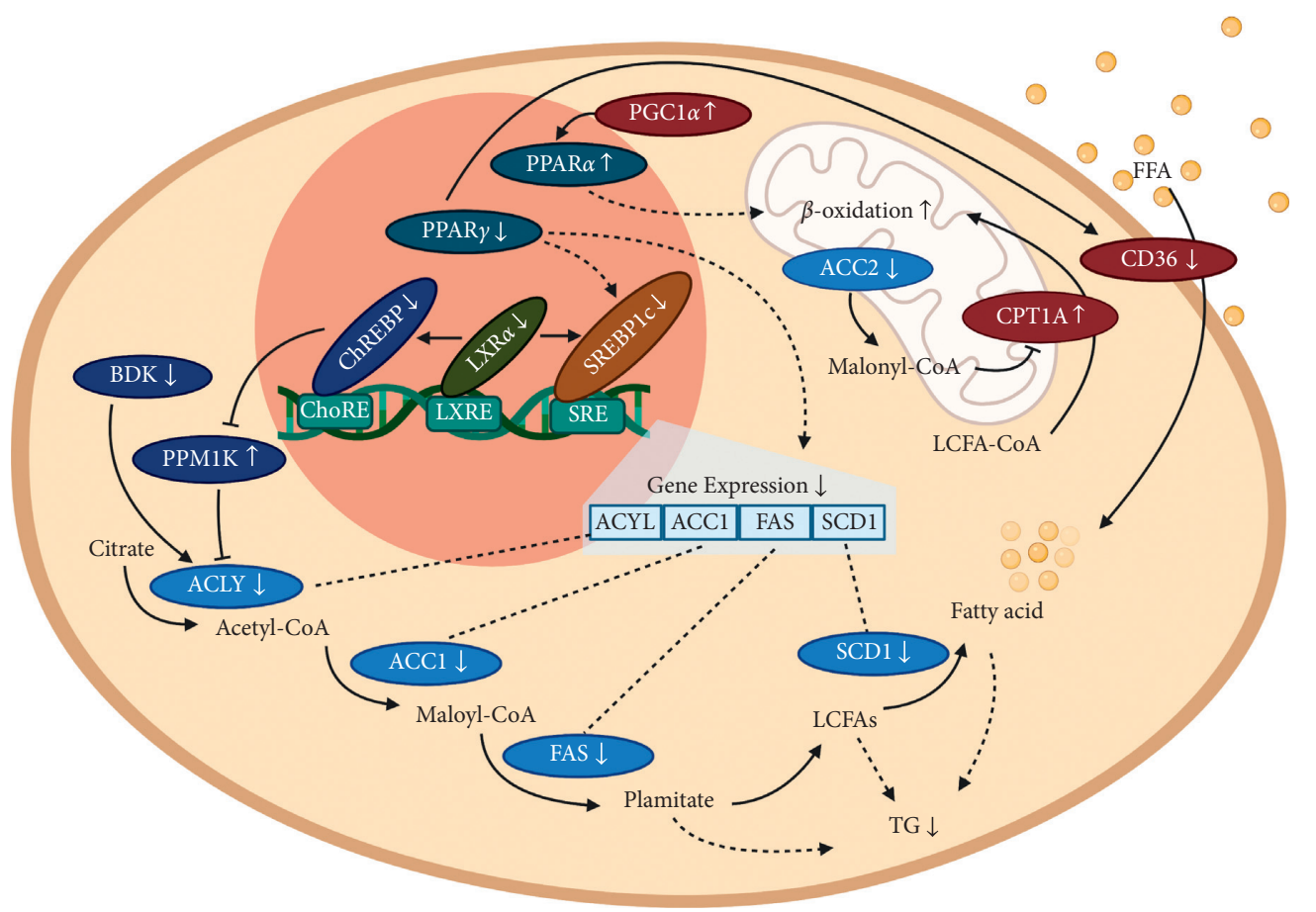

Figure 7: Effect of cinnamic acid (CA) on hepatic lipid metabolism pathways investigated in this study. According to this study, in hepatocytes, CA downregulates the following factors: ATP-citrate lyase (ACLY), acetyl-CoA carboxylase 1 (ACC1), ACC2, fatty acid synthase (FAS), stearoyl-CoA desaturase 1 (SCD1), sterol regulatory element-binding protein 1c (SREBP1c), carbohydrate-responsive element-binding protein (ChREBP), liver X receptor $\alpha(\mathrm{LXR} \alpha)$, peroxisome proliferator-activated receptor $\gamma(\operatorname{PPAR} \gamma)$, branched-chain ketoacid dehydrogenase kinase (BDK), and CD36. CA upregulates the following factors: branched-chain ketoacid dehydrogenase phosphatase (PPM1K), carnitine palmitoyltransferase-1A (CPT1A), peroxisome proliferator-activated receptor $\alpha$ (PPAR $\alpha$ ), and peroxisome proliferator-activated receptor- $\gamma$ coactivator $1 \alpha(\mathrm{PGC} 1 \alpha)$. The suppressed lipogenesis decreased fatty acid intake and boosted fatty acid oxidation contribute to the decreased triglyceride (TG) level in the liver. LCFA: long-chain fatty acid; FFA: free fatty acid; $\uparrow:$ upregulated; $\downarrow$ : downregulated.

response elements, and LXRs bind to LXR response elements, all located in the promoter region of lipogenesis genes, and thereby upregulate their target genes [6, 46, 47]. LXR $\alpha$ is mainly expressed in the liver and other lipogenic tissues [48] and may also activate SREBP1c and ChREBP $[49,50]$. Furthermore, PPAR $\gamma$ is also considered to be an agonist of SREBP1c, as hepatic deletion of PPAR $\gamma$ downregulated SREBP1c, SCD1, and ACC [51]. Our experiments revealed that CA decreased the expression of transcription factors of lipogenesis genes, consistent with the downregulation of their target genes. In addition, BDK and PPM1K are two kinases that coregulate ACLY activity, and hepatic BDK overexpression may lead to excessive DNL. The BDK : PPM1K ratio is believed to be a bioindicator of DNL and metabolic disorder phenotype, and the ratio can be increased by ChREBP [52]. CA downregulated BDK and upregulated PPM1K, which led to a decreased BDK: PPM1K ratio. This may also indicate its inhibitory effect on the transcription factor ChREBP, as well as reflecting CA's therapeutic effects against obesity.

TG accumulation may also be attributed to an increased exocellular fatty acid intake rate. Fatty acids are taken up by hepatocytes through several membrane proteins such as CD36, fatty acid translocase, and fatty acid-binding proteins [53]. In obese rats, CD36 mRNA expression is positively related to the IHTG level and liver steatosis severity [54]. As
PPAR $\gamma$ promotes CD36 transcription in the liver $[55,56]$ and PPAR $\gamma$ was downregulated in the CA group, we investigated the expression of its transcriptional target, CD36. The results showed that CD36 mRNA was significantly downregulated as predicted, indicating that CA may also inhibit the fatty acid intake of hepatocytes.

Fatty acids are principally consumed in the liver, via fatty acid $\beta$-oxidation, which mainly takes place in the mitochondria [8]. LCFAs are activated by converting them to LCFA-CoA by long-chain acyl-CoA synthetases [57] and they are then transferred to mitochondria by CPT1A [58]. PGC1 $\alpha$ is a coactivator of $\operatorname{PPAR} \alpha$, which plays an important role in fatty acid oxidation [59]. Deletion of PPAR $\alpha$ decreased hepatic fatty acid $\beta$-oxidation and aggravated hepatic steatosis in mice [60]. In our $\mathrm{db} / \mathrm{db}$ mice, CA treatment was shown to remarkably increase the CPT1A mRNA and protein expression, as well as increasing the mRNA expression of PGC1 $\alpha$ and PPAR $\alpha$. Additionally, CA treatment downregulated ACC2 mRNA expression, which, as discussed above, generates malonyl-CoA and inhibits the activity of CPT1A (Figure 7).

In addition, $\mathrm{CA}$ is believed to be of relatively low toxicity $[13,15,22]$, and novel formulations are being developed to boost its bioavailability [11]. Thus, CA may be an ideal alternative treatment for NAFLD. However, further experiments, especially comprehensive investigations, such as 
omics investigations, are still required to explore the mechanisms of the beneficial effects in more detail. It is also necessary to determine the toxic and effective dosages of CA prior to its clinical use.

\section{Conclusion}

In conclusion, this study examined CA's effect on lipid metabolism in OA-treated HepG2 cells and mice with NAFLD and investigated the underlying mechanisms. CA showed a therapeutic effect against hyperlipidemia both in vitro and in vivo. In terms of the possible mechanisms, CA downregulated the transcription factors PPAR $\gamma$, SREBP, LXR $\alpha$, and ChREBP, and their target genes ACLY, ACC, FAS, and SCD1. CA also upregulated PGC1 $\alpha, \operatorname{PPAR} \alpha$, and CPT1A and downregulated CD36. Taking all the evidence together, it is presumed that CA suppresses IHTG accumulation and ameliorates NAFLD by inhibiting lipogenesis and fatty acid intake, as well as promoting hepatic fatty acid oxidation.

\section{Abbreviations}

$\begin{array}{ll}\text { ACC: } & \text { Acetyl-CoA carboxylase } \\ \text { ACLY: } & \text { ATP-citrate lyase } \\ \text { BDK: } & \text { Branched-chain ketoacid dehydrogenase kinase } \\ \text { BSA: } & \text { Bovine serum albumin } \\ \text { CA: } & \text { Cinnamic acid } \\ \text { ChREBP: } & \text { Carbohydrate-responsive element-binding } \\ & \text { protein } \\ \text { CMC: } & \text { Carboxymethyl cellulose } \\ \text { CPT1A: } & \text { Carnitine palmitoyltransferase-1A } \\ \text { DAB: } & \text { 3,3'-Diaminobenzidine } \\ \text { DNL: } & \text { De novo lipogenesis } \\ \text { EDTA: } & \text { Ethylenediaminetetraacetic acid } \\ \text { FAS: } & \text { Fatty acid synthase } \\ \text { FFA: } & \text { Free fatty acid } \\ \text { GAPDH: } & \text { Glyceraldehyde } 3 \text {-phosphate dehydrogenase } \\ \text { HDL: } & \text { High-density lipoprotein } \\ \text { IHTG: } & \text { Intrahepatic triglyceride } \\ \text { LCFA: } & \text { Long-chain fatty acid } \\ \text { LDL: } & \text { Low-density lipoprotein } \\ \text { LXRs: } & \text { Liver X receptors } \\ \text { NAFLD: } & \text { Nonalcoholic fatty liver disease } \\ \text { PGC1 } \alpha: & \text { Peroxisome proliferator-activated receptor- } \gamma \\ \text { PPAR } \alpha: & \text { Peroxisome proliferator-activated receptor } \alpha \\ \text { PPAR } \gamma: & \text { Peroxisome proliferator-activated receptor } \gamma \\ \text { PPM1K: } & \text { Branched-chain ketoacid dehydrogenase } \\ & \text { phosphatase } \\ \text { RIPA: } & \text { Radioimmunoprecipitation assay } \\ \text { SCD1: } & \text { Stearoyl-CoA desaturase } 1 \\ \text { SREBP1c: } & \text { Sterol regulatory element-binding protein } 1 c \\ \text { TC: } & \text { Total cholesterol } \\ \text { TG: } & \text { Triglyceride. } \\ & \end{array}$

\section{Data Availability}

The datasets used and/or analyzed during the current study are available from the corresponding author on reasonable request. A preprint of the manuscript has previously been published [61].

\section{Ethical Approval}

All animal experiments were approved by the Animal Care and Ethics Committee of Beijing University of Traditional Chinese Medicine (approval code no. BUCM-420190931002-1088).

\section{Conflicts of Interest}

The authors declare that they have no conflicts of interest.

\section{Authors' Contributions}

Y.W. and M.W. conceptualized the study. Y.W., M.W., and T.Y. developed the methodology. L.Q. performed validation. Y.W., M.W., T.Y., Y.H., and D.Z. performed investigation. Y.W. wrote the original draft. T.Y. and L.Q. reviewed and edited the article. Y.W. and T.Y. performed visualization. L.W. and T.L. supervised the study. L.W. and T.L. were responsible for funding acquisition. All the authors have read and agreed to the published version of the manuscript. You Wu, Minghui Wang, and Tao Yang contributed equally and share the first authorship.

\section{Acknowledgments}

The authors used BioRender.com to generate the illustration in Figure 7. The authors would like to thank Prof. Yan-ling Zhao (Department of Pharmacy, Fifth Medical Center, General Hospital of Chinese PLA, Beijing, China) for her advice on this research, and they are also grateful to Lei Ding (Key Laboratory of Health Cultivation of the Ministry of Education, Beijing University of Chinese Medicine) for his assistance with the animal experiments. This research was funded by the Creation and Talent Introduction Base of Prevention and Treatment of Diabetes and Its Complications with Traditional Chinese Medicine (Grant no. B20055).

\section{References}

[1] J. Ertle, A. Dechêne, J.-P. Sowa et al., "Non-alcoholic fatty liver disease progresses to hepatocellular carcinoma in the absence of apparent cirrhosis," International Journal of Cancer, vol. 128, no. 10, pp. 2436-2443, 2011.

[2] Z. M. Younossi, A. B. Koenig, D. Abdelatif, Y. Fazel, L. Henry, and M. Wymer, "Global epidemiology of nonalcoholic fatty liver disease-meta-analytic assessment of prevalence, incidence, and outcomes," Hepatology, vol. 64, no. 1, pp. 73-84, 2016.

[3] T. G. Cotter and M. Rinella, "Nonalcoholic fatty liver disease 2020: the state of the disease," Gastroenterology, vol. 158, no. 7, pp. 1851-1864, 2020.

[4] E. Fabbrini, S. Sullivan, and S. Klein, "Obesity and nonalcoholic fatty liver disease: biochemical, metabolic, and clinical implications," Hepatology, vol. 51, no. 2, pp. 679-689, 2010.

[5] K. M. Korenblat, E. Fabbrini, B. S. Mohammed, and S. Klein, "Liver, muscle, and adipose tissue insulin action is directly 
related to intrahepatic triglyceride content in obese subjects," Gastroenterology, vol. 134, no. 5, pp. 1369-1375, 2008.

[6] Y. Wang, J. Viscarra, S.-J. Kim, and H. S. Sul, "Transcriptional regulation of hepatic lipogenesis," Nature Reviews Molecular Cell Biology, vol. 16, no. 11, pp. 678-689, 2015.

[7] L. Yang, X. Zhang, M. Liao, and Y. Hao, "Echinacoside improves diabetic liver injury by regulating the AMPK/SIRT1 signaling pathway in $\mathrm{db} / \mathrm{db}$ mice," Life Sciences, vol. 271, Article ID 119237, 2021.

[8] M. Alves-Bezerra and D. E. Cohen, "Triglyceride metabolism in the liver," Comprehensive Physiology, vol. 8, pp. 1-8, 2017.

[9] D. Bickers, P. Calow, H. Greim et al., "A toxicologic and dermatologic assessment of cinnamyl alcohol, cinnamaldehyde and cinnamic acid when used as fragrance ingredients," Food and Chemical Toxicology, vol. 43, no. 6, pp. 799-836, 2005.

[10] S. Adisakwattana, "Cinnamic acid and its derivatives: mechanisms for prevention and management of diabetes and its complications," Nutrients, vol. 9, 2017.

[11] H. Wang, Q. Li, W. Deng et al., "Self-nanoemulsifying drug delivery system of trans-cinnamic acid: formulation development and pharmacodynamic evaluation in alloxan-induced type 2 diabetic rat model," Drug Development Research, vol. 76, no. 2, pp. 82-93, 2015.

[12] S. Chandra, A. Roy, M. Jana, and K. Pahan, "Cinnamic acid activates PPAR $\alpha$ to stimulate lysosomal biogenesis and lower amyloid plaque pathology in an Alzheimer's disease mouse model," Neurobiology of Disease, vol. 124, pp. 379-395, 2019.

[13] J. A. Hoskins, "The occurrence, metabolism and toxicity of cinnamic acid and related compounds," Journal of Applied Toxicology, vol. 4, no. 6, pp. 283-292, 1984.

[14] J. Guzman, "Natural cinnamic acids, synthetic derivatives and hybrids with antimicrobial activity," Molecules, vol. 19, no. 12, pp. 19292-19349, 2014.

[15] M. Patil, A. S. Choudhari, S. Pandita, M. A. Islam, P. Raina, and R. Kaul-Ghanekar, "Cinnamaldehyde, cinnamic acid, and cinnamyl alcohol, the bioactives of Cinnamomum cassia exhibit HDAC8 inhibitory activity: an in vitro and in silico study," Pharmacognosy Magazine, vol. 13, pp. S645-s651, 2017.

[16] L. Liu, W. R. Hudgins, S. Shack, M. Q. Yin, and D. Samid, "Cinnamic acid: a natural product with potential use in cancer intervention," International Journal of Cancer, vol. 62, no. 3, pp. 345-350, 1995.

[17] R. de Cássia da Silveira e Sá, L. Andrade, R. Dos Reis Barreto de Oliveira, and D. de Sousa, "A review on anti-inflammatory activity of phenylpropanoids found in essential oils," Molecules, vol. 19, no. 2, pp. 1459-1480, 2014.

[18] M. Sova, "Antioxidant and antimicrobial activities of cinnamic acid derivatives," Mini-Reviews in Medicinal Chemistry, vol. 12, no. 8, pp. 749-767, 2012.

[19] A. A. Hemmati, S. Alboghobeish, and A. Ahangarpour, "Effects of cinnamic acid on memory deficits and brain oxidative stress in streptozotocin-induced diabetic mice," The Korean Journal of Physiology \& Pharmacology, vol. 22, no. 3, pp. 257-267, 2018.

[20] H. G. Anlar, M. Bacanli, T. Çal et al., "Effects of cinnamic acid on complications of diabetes," Turkish Journal of Medical Sciences, vol. 48, pp. 168-177, 2018.

[21] K. Mnafgui, A. Derbali, S. Sayadi, N. Gharsallah, A. Elfeki, and N. Allouche, "Anti-obesity and cardioprotective effects of cinnamic acid in high fat diet- induced obese rats," Journal of Food Science and Technology, vol. 52, no. 7, pp. 4369-4377, 2015.
[22] Z. Wang, S. Ge, S. Li, H. Lin, and S. Lin, "Anti-obesity effect of trans-cinnamic acid on HepG2 cells and HFD-fed mice," Food and Chemical Toxicology, vol. 137, Article ID 111148, 2020.

[23] L. Zhao, S.-j. Jiang, F.-e. Lu et al., "Effects of berberine and cinnamic acid on palmitic acid-induced intracellular triglyceride accumulation in NIT-1 pancreatic $\beta$ cells," Chinese Journal of Integrative Medicine, vol. 22, no. 7, pp. 496-502, 2016.

[24] N. H. Kang, S. Mukherjee, and J. W. Yun, “Trans-cinnamic acid stimulates white fat browning and activates Brown adipocytes," Nutrients, vol. 11, 2019.

[25] P. K. Prabhakar and M. Doble, "Interaction of cinnamic acid derivatives with commercial hypoglycemic drugs on 2deoxyglucose uptake in 3T3-L1 adipocytes," Journal of Agricultural and Food Chemistry, vol. 59, no. 18, pp. 9835-9844, 2011.

[26] D. G. Buyco, J. Martin, S. Jeon, R. Hooks, C. Lin, and R. Carr, "Experimental models of metabolic and alcoholic fatty liver disease," World Journal of Gastroenterology, vol. 27, no. 1, pp. 1-18, 2021.

[27] C. Peng, A. G. Stewart, O. L. Woodman, R. H. Ritchie, and C. X. Qin, "Non-alcoholic steatohepatitis: a review of its mechanism, models and medical treatments," Frontiers in Pharmacology, vol. 11, Article ID 603926, 2020.

[28] L. Guo, J. S. Kang, Y. H. Park et al., "S-petasin inhibits lipid accumulation in oleic acid-induced HepG2 cells through activation of the AMPK signaling pathway," Food \& Function, vol. 11, no. 6, pp. 5664-5673, 2020.

[29] J. Zhang, S.-d. Zhang, P. Wang et al., "Pinolenic acid ameliorates oleic acid-induced lipogenesis and oxidative stress via AMPK/SIRT1 signaling pathway in HepG2 cells," European Journal of Pharmacology, vol. 861, Article ID 172618, 2019.

[30] E. Esposito, W. Li, E. T. Mandeville et al., "Potential circadian effects on translational failure for neuroprotection," Nature, vol. 582, no. 7812, pp. 395-398, 2020.

[31] R. B. Kasetti, S. A. Nabi, S. Swapna, and C. Apparao, "Cinnamic acid as one of the antidiabetic active principle(s) from the seeds of Syzygium alternifolium," Food and Chemical Toxicology, vol. 50, no. 5, pp. 1425-1431, 2012.

[32] R. M. Hafizur, A. Hameed, M. Shukrana et al., "Cinnamic acid exerts anti-diabetic activity by improving glucose tolerance in vivo and by stimulating insulin secretion in vitro," Phytomedicine, vol. 22, no. 2, pp. 297-300, 2015.

[33] A. L. Birkenfeld and G. I. Shulman, "Nonalcoholic fatty liver disease, hepatic insulin resistance, and type 2 diabetes," Hepatology, vol. 59, no. 2, pp. 713-723, 2014.

[34] D. Goldner and J. E. Lavine, "Nonalcoholic fatty liver disease in children: unique considerations and challenges," Gastroenterology, vol. 158, no. 7, pp. 1967-1983, 2020.

[35] J.-G. Fan, S.-U. Kim, and V. W.-S. Wong, "New trends on obesity and NAFLD in Asia," Journal of Hepatology, vol. 67, no. 4, pp. 862-873, 2017.

[36] F. Magkos, M. F. Hjorth, and A. Astrup, "Diet and exercise in the prevention and treatment of type 2 diabetes mellitus," Nature Reviews Endocrinology, vol. 16, no. 10, pp. 545-555, 2020.

[37] B. S. Lakshmi, S. Sujatha, S. Anand et al., "Cinnamic acid, from the bark of Cinnamomum cassia, regulates glucose transport via activation of GLUT4 on L6 myotubes in a phosphatidylinositol 3-kinase-independent manner," Journal of Diabetes, vol. 1, no. 2, pp. 99-106, 2009.

[38] D.-W. Huang, S.-C. Shen, and J. S.-B. Wu, "Effects of caffeic acid and cinnamic acid on glucose uptake in insulin-resistant 
mouse hepatocytes," Journal of Agricultural and Food Chemistry, vol. 57, no. 17, pp. 7687-7692, 2009.

[39] S. Adisakwattana, P. Chantarasinlapin, H. Thammarat, and S. Yibchok-Anun, "A series of cinnamic acid derivatives and their inhibitory activity on intestinal $\alpha$-glucosidase," Journal of Enzyme Inhibition and Medicinal Chemistry, vol. 24, no. 5, pp. 1194-1200, 2009.

[40] Z. Song, A. M. Xiaoli, and F. Yang, "Regulation and metabolic significance of de novo lipogenesis in adipose tissues," $\mathrm{Nu}$ trients, vol. 10, 2018.

[41] G. Solinas, J. Borén, and A. G. Dulloo, "De novo lipogenesis in metabolic homeostasis: more friend than foe?" Molecular Metabolism, vol. 4, no. 5, pp. 367-377, 2015.

[42] L. Abu-Elheiga, W. R. Brinkley, L. Zhong, S. S. Chirala, G. Woldegiorgis, and S. J. Wakil, "The subcellular localization of acetyl-CoA carboxylase 2," Proceedings of the National Academy of Sciences, vol. 97, no. 4, pp. 1444-1449, 2000.

[43] D. B. Savage, C. S. Choi, V. T. Samuel et al., "Reversal of dietinduced hepatic steatosis and hepatic insulin resistance by antisense oligonucleotide inhibitors of acetyl-CoA carboxylases 1 and 2," Journal of Clinical Investigation, vol. 116, no. 3, pp. 817-824, 2006.

[44] L. Rui, "Energy metabolism in the liver," Comprehensive Physiology, vol. 4, pp. 177-197, 2014.

[45] F. W. B. Sanders and J. L. Griffin, "De novo lipogenesis in the liver in health and disease: more than just a shunting yard for glucose," Biological Reviews, vol. 91, no. 2, pp. 452-468, 2016.

[46] M.-J. Latasa, M. J. Griffin, Y. S. Moon, C. Kang, and H. S. Sul, "Occupancy and function of the -150 sterol regulatory element and -65 E-box in nutritional regulation of the fatty acid synthase gene in living animals," Molecular and Cellular Biology, vol. 23, no. 16, pp. 5896-5907, 2003.

[47] L. Ma, N. G. Tsatsos, and H. C. Towle, "Direct role of ChREBP.Mlx in regulating hepatic glucose-responsive genes," Journal of Biological Chemistry, vol. 280, no. 12, pp. 12019-12027, 2005.

[48] P. J. Willy, K. Umesono, E. S. Ong, R. M. Evans, R. A. Heyman, and D. J. Mangelsdorf, "LXR, a nuclear receptor that defines a distinct retinoid response pathway," Genes \& Development, vol. 9, no. 9, pp. 1033-1045, 1995.

[49] G. Chen, G. Liang, J. Ou, J. L. Goldstein, and M. S. Brown, "Central role for liver $\mathrm{X}$ receptor in insulin-mediated activation of Srebp-1c transcription and stimulation of fatty acid synthesis in liver," Proceedings of the National Academy of Sciences, vol. 101, no. 31, pp. 11245-11250, 2004.

[50] J.-Y. Cha and J. J. Repa, "The liver X receptor (LXR) and hepatic lipogenesis. The carbohydrate-response elementbinding protein is a target gene of LXR," Journal of Biological Chemistry, vol. 282, no. 1, pp. 743-751, 2007.

[51] E. Moran-Salvador, M. Lopez-Parra, V. Garcia-Alonso et al., "Role for PPAR $\gamma$ in obesity-induced hepatic steatosis as determined by hepatocyte- and macrophage-specific conditional knockouts," FASEB Journal, vol. 25, pp. 2538-2550, 2011.

[52] P. J. White, R. W. McGarrah, P. A. Grimsrud et al., "The BCKDH kinase and phosphatase integrate BCAA and lipid metabolism via regulation of ATP-citrate lyase," Cell Metabolism, vol. 27, no. 6, pp. 1281-1293, 2018.

[53] M. W. Bradbury, "Lipid metabolism and liver inflammation. I. Hepatic fatty acid uptake: possible role in steatosis," American Journal of Physiology-Gastrointestinal and Liver Physiology, vol. 290, no. 2, pp. G194-G198, 2006.

[54] X. Buqué, M. J. Martínez, A. Cano et al., "A subset of dysregulated metabolic and survival genes is associated with severity of hepatic steatosis in obese Zucker rats," Journal of Lipid Research, vol. 51, no. 3, pp. 500-513, 2010.

[55] P. Tontonoz, L. Nagy, J. G. A. Alvarez, V. A. Thomazy, and R. M. Evans, "PPAR $\gamma$ promotes monocyte/macrophage differentiation and uptake of oxidized LDL," Cell, vol. 93, no. 2, pp. 241-252, 1998.

[56] D. B. Savage, "PPAR gamma as a metabolic regulator: insights from genomics and pharmacology," Expert Reviews in Molecular Medicine, vol. 7, pp. 1-16, 2005.

[57] L. O. Li, J. M. Ellis, H. A. Paich et al., "Liver-specific loss of long chain acyl-CoA synthetase-1 decreases triacylglycerol synthesis and $\beta$-oxidation and alters phospholipid fatty acid composition," Journal of Biological Chemistry, vol. 284, no. 41, pp. 27816-27826, 2009.

[58] J. D. McGarry and D. W. Foster, "Regulation of hepatic fatty acid oxidation and ketone body production," Annual Review of Biochemistry, vol. 49, no. 1, pp. 395-420, 1980.

[59] J. T. Rodgers, C. Lerin, W. Haas, S. P. Gygi, B. M. Spiegelman, and P. Puigserver, "Nutrient control of glucose homeostasis through a complex of PGC- $1 \alpha$ and SIRT1," Nature, vol. 434, no. 7029, pp. 113-118, 2005.

[60] T. C. Leone, C. J. Weinheimer, and D. P. Kelly, “A critical role for the peroxisome proliferator-activated receptor (PPAR) in the cellular fasting response: the PPAR -null mouse as a model of fatty acid oxidation disorders," Proceedings of the National Academy of Sciences, vol. 96, no. 13, pp. 7473-7478, 1999.

[61] Y. Wu, M.-h. Wang, T. Yang et al., Cinnamic Acid Ameliorates Nonalcoholic Fatty Liver Disease by Suppressing Hepatic Lipogenesis and Promoting Fatty Acid Oxidation, Research Square, Durham, NC, USA, 2021. 